\title{
Novel Gas Barrier SiOC Coating to PET Bottles through a Hot Wire CVD Method
}

\author{
Masaki Nakaya, ${ }^{1}$ Kenji Kodama, ${ }^{2}$ Shigeo Yasuhara, ${ }^{2}$ and Atsushi Hotta ${ }^{3}$ \\ ${ }^{1}$ Research Laboratories for Packaging Technologies, RङD Department, Kirin Co., Ltd., Technovillage 3F, 1-17-1 Namamugi, \\ Tsurumi-ku, Yokohama 230-8628, Japan \\ ${ }^{2}$ Japan Advanced Chemicals Ltd., SIC-3 3114, 1880-2 Kamimizo, Chuo-ku, Sagamihara-shi, Kanagawa 252-0243, Japan \\ ${ }^{3}$ Department of Mechanical Engineering, Faculty of Science and Technology, Keio University, 3-14-1 Hiyoshi, \\ Kohoku-ku, Yokohama 223-8522, Japan
}

Correspondence should be addressed to Masaki Nakaya; m-nakaya@kirin.co.jp

Received 31 March 2016; Revised 31 May 2016; Accepted 2 June 2016

Academic Editor: Zhong-Ming Li

Copyright (C) 2016 Masaki Nakaya et al. This is an open access article distributed under the Creative Commons Attribution License, which permits unrestricted use, distribution, and reproduction in any medium, provided the original work is properly cited.

In an attempt to enhance the gas barrier enhancement of plastic containers such as poly(ethylene terephthalate) bottles, a novel method was found using a hot wire CVD technique, where tantalum wire is heated and exposed to a gas flow of vinyl silane. The resultant SiOC thin film was confirmed to characteristically contain $\mathrm{Si}$-Si bonds in its surface and demonstrate a remarkably and highly practical decrease of the permeation of various gas through poly(ethylene terephthalate) bottles.

\section{Introduction}

Due to the gas permeable nature of plastic containers, various gas barrier enhancement technologies are pursued based on the requirements in each industry [1]. In the food and beverage industry, PET (poly(ethylene terephthalate)) bottles are among the most intensive category of plastic containers for gas barrier enhancement study based on the industrial scale of use. Nowadays, the majority of beverage plastic containers consist of PET bottles as a global trend [2]. This trend is derived from economic drivers in bottle manufacturing and wide applicability to different beverage categories. Along with this trend, the demand for high gas barrier PET bottles has been increasing. One reason lies in the global trend in lightweighting, where thinner bottle wall favors the enhancement of gas barrier. Another reason is a gradual increase of the applications of PET bottle formats to remarkably sensitive products to gas permeation in terms of shelf-life required for each of the products. These products are, for instance, beer, wine, and juice, and their product quality is affected by the permeation of gas such as oxygen and carbon dioxide and flavor components [3].
Main approach for the gas barrier enhancement of PET bottles includes thin film coating, multilayer, oxygen scavengers, and blending [4]. The advantageous characteristics of thin film coatings in this field lie in the relatively high degree of gas barrier and the relatively wide coverage of product categories as well as the relatively high degree of recyclability of PET bottles. To the contrary, the relatively high capital expenditure for the installment of specific machines based on plasma assisted chemical vapor deposition (CVD) processes is the disadvantage of coatings. As a result, a novel process of thin film coating has been demanded which provides possible reduced capital expenditure and maintains or improves the gas barrier performance of conventional thin film coatings mentioned above.

One approach to the novel process is expected to be found in a hot wire CVD technique, because its potentially economical device formats and expected high barrier performance have recently attracted increasing attention [5]. The possible reduced capital expenditure for bottle coating machines is expected based on the relatively simple device formats without high frequency power supplies and the resultant use of plasma, which increases the relative complexity of 
coating devices and the resultant economic burden. The key technique in the hot wire CVD lies in the combination of wire and material gas species. Some proposals have been made in hot wire techniques such as the combination of tungsten and silane gas [6] and tungsten and hexamethyldisilazane $[7,8]$. However, the explosive nature of silane gas involves the practical difficulty to the use inside the factories of typical PET bottle manufactures. Also, PET bottles lack the heat resistance required or sufficient deposition rate for the formation of the barrier coating based on the tungsten and hexamethyldisilazane approach mentioned above. As a result, a novel combination of hot wire and material gas species is demanded in the hot wire CVD approach.

It should be noted that the current thin films are formed based on plasma assisted CVD techniques, and these films can be roughly divided as carbon $[1,4,9-11]$ and $\mathrm{SiOx}[1,4,12$, 13] coatings, both of which are formed over the inner surface of PET bottles and in contact with beverage liquids filled. The former has a certain metallic carbon color tint, which may lead to the avoidance of use due to the psychological impact on container appearance, while the latter tends to show a certain limited barrier performance and the resultant limited applications derived from the instability in some beverage liquids, for example, a type of tea close to the neutral in terms of $\mathrm{pH}$ [14]. In brief, a novel coating technique is demanded for a thin film which is colorless and physiochemically stable in contact with various beverage liquids, in an economical manner, especially in terms of reduced capital expenditure, to install specific machines.

Also, a type of material gas available for hot wire CVD has been demanded in food and beverage industry which is not highly explosive or poisonous and can form gas barrier thin films with appropriate hot wire. Vinyl silane has a silyl function in the molecule and, in this sense, a similar chemical structure to monosilane, a known material gas for remarkably high gas barrier films, for example, $\mathrm{SiNx}$, as mentioned above. However, the vinyl function in vinyl silane increases chemical stability; in other words, it provides no explosive nature under atmospheric conditions. This chemically more stable nature of vinyl silane is practically expected to enable a safe operation in PET bottle manufacturing factories. We paid attention to these characteristic aspects and attempted to form a gas barrier thin film onto a PET bottle.

\section{Materials and Methods}

2.1. Preparation of PET Bottles. $500 \mathrm{~mL}$ PET bottles of typical shape and weight $(29 \mathrm{~g})$ for carbonated soft drinks were manufactured using a preform injection machine, KS100T Kata System Co., Ltd., and a blow molding machine, LB01E, KHS. The resultant bottle had height of ca. $210 \mathrm{~mm}$, diameter of ca. $66 \mathrm{~mm}$, and thickness of $0.035 \mathrm{~mm}$. Figure 1 shows the appearance of the bottles manufactured.

2.2. Thin Film Formation onto a PET Bottle. Tantalum wire of diameter of $0.5 \mathrm{~mm}$, supplied by Plansee Japan Co., Ltd., was cut to be a pair with length of $420 \mathrm{~mm}$ and $440 \mathrm{~mm}$. The wire pair was set to a specifically designed coating device by

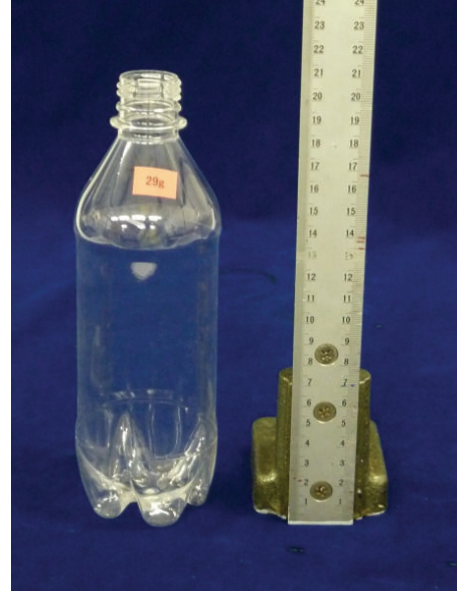

FIGURE 1: Appearance of PET bottles used in this study (same picture as Figure 1 of a previous study [15]).

authors (Figure 2). Inside a bottle, each wire was supported in an insulated state with a gas inlet pipe made of ceramic (alumina) with outer diameter of $6.0 \mathrm{~mm}$ and the inner diameter of $4.0 \mathrm{~mm}$ and they were crossly placed to each other in a noncontact manner, so that the wire surface is placed in a position generally $20 \mathrm{~mm}$ apart from the most parts of the bottle inner wall. The bottle substrate, the wires, and the gas inlet pipe were set inside the vacuum chamber connected to vacuum pumps.

Vinyl silane $\left(\mathrm{H}_{3} \mathrm{Si}-\mathrm{CH}=\mathrm{CH}_{2}\right.$, Figure 3), which is gaseous under the atmospheric pressure or below at room temperature, was synthesized by Japan Advanced Chemicals Co., Ltd. The flow rate of gas was controllable through a mass flow controller in sccm (cubic centimeter under standard temperature and pressure per minute) unit, which is installed in the middle of the gas inlet pipe and a gas cylinder. For the optimization of gas flow rate in terms of oxygen gas barrier, each one bottle was coated for different gas flow rate ranging from $30 \mathrm{sccm}$ to $90 \mathrm{sccm}$.

Thin film was formed through heating the wires with DC power supply, HX0500-30, Takasago Ltd. The temperature of the heated wires was measured with a handy radiation thermometer, TR-630A, Konica Minolta Inc., through a window made of $\mathrm{Pyrex}^{\circledR}$ glass which forms a part of the chamber.

Figure 2 shows schematic illustration of hot wire CVD chamber designed for PET bottle coating. Hot wires through electroheating with DC power decompose material gas inside the bottle and thin films are formed over the inner surface of PET bottles.

2.3. Measurement of Deposition Rate. The deposition rate of thin film formed in the above-mentioned manner was measured using partially masked silicon wafers placed on the inner surface of the center of the body part of PET bottles as described in a previous study [15]. The difference in height between the unmasked and the masked parts was detected using a contact-type thickness meter, $\alpha$-step, KLA-Tencor 


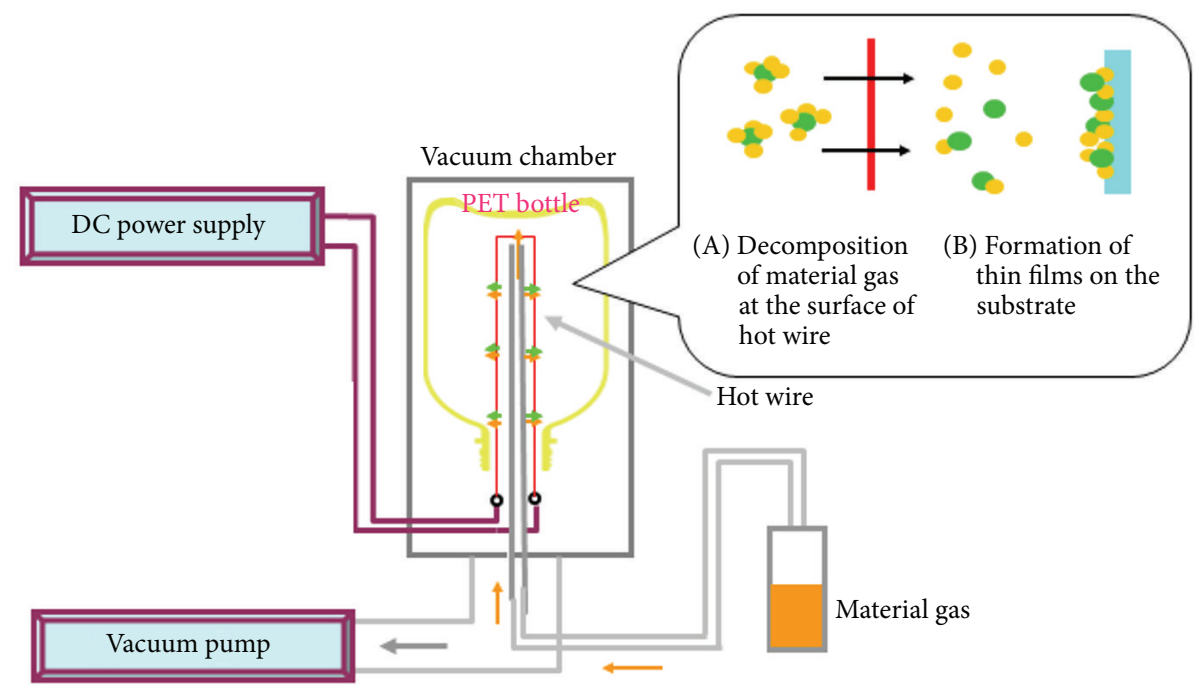

FIGURE 2: Schematic structure of coating device used in this study. Inside a bottle placed in a vacuum chamber, hot filaments connected to a power supply were fixed along a gas supply pipe connected to a material gas container. (A) Supplied material gas is decomposed in contact with hot wire and (B) the decomposed molecules form a thin film on the inner surface of PET bottles.<smiles>C=CC</smiles>

Figure 3: Chemical structure of vinyl silane.

Corporation. The average of deposition rate obtained from three samples was adopted.

\subsection{Measurement of Oxygen Barrier Properties of PET Bottles.} The oxygen transmission rate (OTR) of a PET bottle was measured based on ASTM F-1307 using an Oxtran 2/21 device, Mocon Co., Ltd., under conditions of $23^{\circ} \mathrm{C}$ and $\mathrm{RH}$ $90 \%$. This is a type of a constant pressure and volume method for containers. In this method, the mouth part of a sample bottle is hermetically sealed to a metal pipe system. One end of the system is connected to the nitrogen gas source, and another is connected to the oxygen detector of the device. Because pure nitrogen constantly passes through the inside of the bottle, the sample volume (including the surface area and the wall thickness) and the oxygen pressure difference between the inside and outside of the sample are controlled to be constant. The resultant OTR, therefore, reflects oxygen permeation through the bottle only. It should be mentioned that the degree of gas barrier enhancement is often expressed in barrier improvement factor (BIF), which is calculated based on the OTR of an uncoated bottle divided by the OTR of a coated bottle to that of an uncoated bottle, from the view of shelf-life extension of commercial products. The average of OTR obtained from three samples was adopted.

2.5. Morphological Characterization of Thin Film Formed. The surface images of the thin film formed on the PET substrate were observed with a scanning electron microscope,
JSM-7600F, JEOL Ltd. The samples were cut from the center of the body part of PET bottles and coated with vaporized osmium. To observe the surface images, the magnification was set to 100,000 times under the conditions of $5 \mathrm{kV}$ for the electron acceleration.

2.6. Chemical Characterization of Thin Film Formed. For the chemical structure of thin film formed, XPS analysis was performed. Samples were cut from the center of the body part of PET bottles coated, and the spectral regions of Si2p, O1s, C1s, and N1s were measured using Quantera SXM, Physical Electronics, Inc., based on AlK $\alpha$ radiation $(1486.6 \mathrm{eV})$.

2.7. Measurement of Water Vapor Barrier Properties of PET Bottles. The water vapor transmission of a PET bottle was determined based on the average rate of the decrease in the weight of three bottles filled with $500 \mathrm{~mL}$ distilled water and stored under the conditions of $23^{\circ} \mathrm{C}$ and $\mathrm{RH} 50 \%$. The weight of each of the filled samples was regularly measured using an electronic balance. The resultant weight loss rate includes water vapor permeation through both bottle and closure parts.

\section{Results}

3.1. Formation of Thin Film with Tantalum and Vinyl Silane. The vacuum chamber including a PET bottle and tantalum wires was vacuumed to $5.0 \mathrm{~Pa}$. The wires were then heated inside the PET bottle to ca. $2000^{\circ} \mathrm{C}$ using a radiation thermometer.

The supply of vinyl silane to the inside of the bottle was adjusted using a mass flow controller to a flow rate ranging from $30 \mathrm{sccm}$ to $90 \mathrm{sccm}$ and kept for 6.0 seconds, followed by the termination of the heating of the wires and the vacuuming of the chamber. 


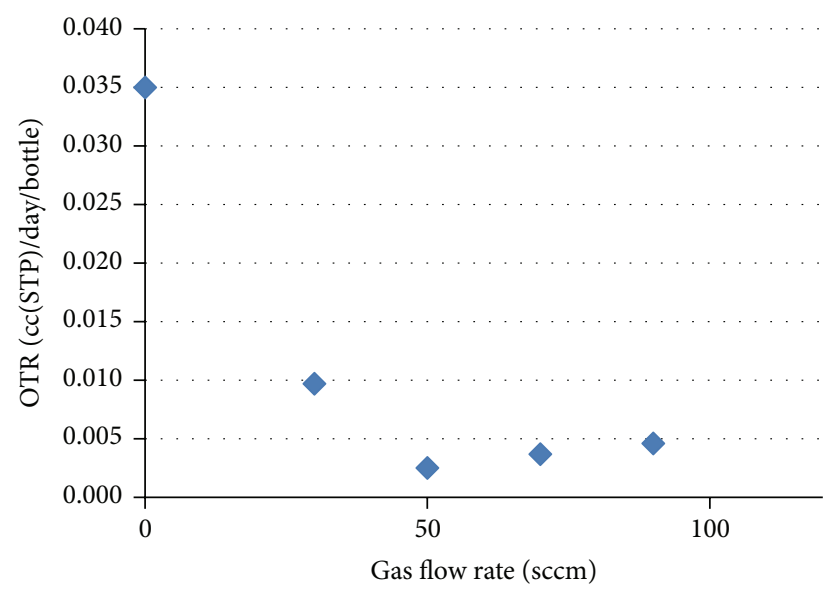

Figure 4: Dependence of the oxygen barrier of coated bottles on gas flow rate. OTR refers to oxygen transmission rate. The unit of OTR, cc(STP)/day/bottle, refers to cubic centimeter at standard temperature and pressure per day per bottle. Gas flow rate of vinyl silane was arranged between 30 and $90 \mathrm{sccm}$, and the resultant OTR of coated bottles was measured. The value of OTR at the gas flow rate of $0 \mathrm{sccm}$ shows the OTR of uncoated bottles.

TABLE 1: Composition of thin film obtained based on XPS spectra.

\begin{tabular}{lc}
\hline & Atomic\% \\
\hline Silicon & 32.9 \\
Oxygen & 29.4 \\
Carbon & 37.4 \\
Nitrogen & Not detected \\
\hline
\end{tabular}

When the resultant bottle was removed from the chamber after the pressure release of the chamber, no tangible deformation was observed in the shape of the coated PET bottles, in spite of vacuuming and heating processes described above.

The formation of a thin film coating was confirmed through visual observation based on a slight golden tint.

3.2. Oxygen Barrier Property of the Thin Film Formed. The result of OTR measurement showed that the highest oxygen gas barrier was achieved at the flow rate of $50 \mathrm{sccm}$ as shown in Figure 4. The resultant bottle showed more than 10 times (15.2 time in BIF) oxygen gas barrier enhancement, indicating highly practical oxygen barrier enhancement for food and beverage application. Based on the coating thickness shown in Figure 5, the deposition rate of the thin film in the center part of the bottle was ca. $6.4 \mathrm{~nm} / \mathrm{sec}$ as shown in Table 1. In the following experiments, the gas flow rate of $50 \mathrm{sccm}$ was used for thin film coating.

3.3. Observation of the Thin Film Formed. To confirm the influence of coating time on oxygen barrier property, thin film was formed under conditions of the gas flow rate of $50 \mathrm{sccm}$ and coating time of $2.0 \mathrm{sec}$. The resultant bottle still showed more than 10 times (11.0 time in BIF) oxygen gas barrier enhancement. In this case, the tint of coating was remarkably reduced as shown in Figure 6.

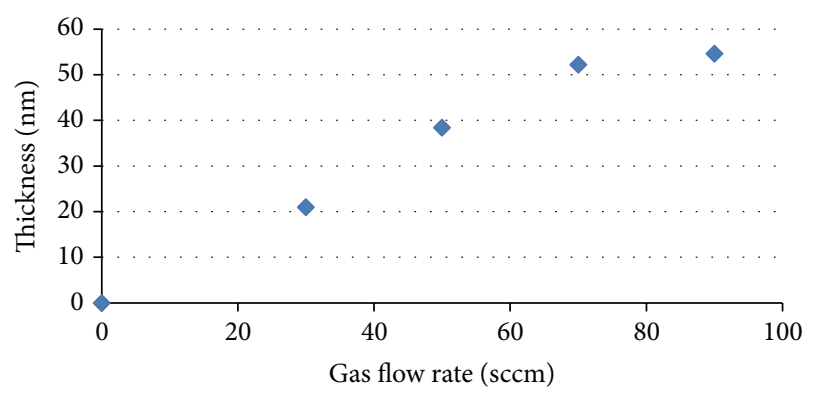

FIgURE 5: Dependence of coating thickness on gas flow rate. The thickness of thin films formed at coating time of $6.0 \mathrm{sec}$ was measured.

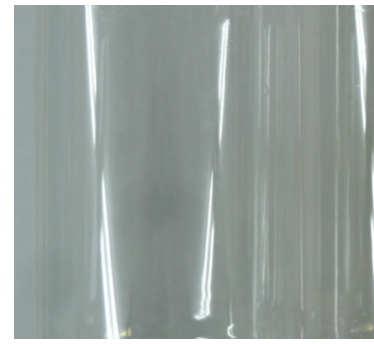

(a)

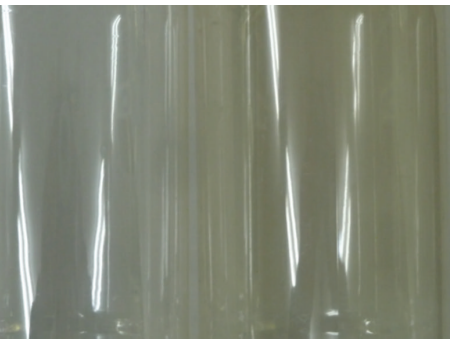

(b)

(c)
Figure 6: The tint derived from thin film coating. Pictures show the body part of (a) uncoated, (b) coated for $2.0 \mathrm{sec}$, and (c) coated for 6.0 sec PET bottles.

The surface of the thin coated film prepared under the same conditions as sample (c) of Figure 6 was observed by the scanning electron microscopy. As shown in Figures 7(a) and $7(b)$, the coated surface observed was smooth, equivalent to the uncoated surface.

3.4. The Chemical Identity of the Thin Film Formed. Table 1 shows the result of XPS analysis for the chemical composition of the surface of thin film formed as described above. The film contains silicon, carbon, oxygen, and hydrogen and can be expressed as a type of SiOC film. Nitrogen component was not detected. Interestingly, XPS analysis indicates that the SiOC film contains $\mathrm{Si}-\mathrm{Si}$ bonds $(99.0 \mathrm{keV})$ at least in its outer surface, as shown in Figure 8.

3.5. Water Vapor Barrier Property of PET Bottles. To confirm the stability of the gas barrier property of the thin film described above, a storage test was performed based on water vapor permeation. In this test, PET bottles were filled with distilled water and sealed with typical commercial plastic closures.

In comparison of the weight derived from water vapor permeation between uncoated and coated samples, the latter showed highly practical water vapor barrier enhancement as shown in Figure 9. It should be mentioned that the steady rate of the weight loss of the coated bottles due to water vapor permeation during the storage period strongly suggests the stability of the thin film coated on the surface of PET bottles in water close to neutral in terms of $\mathrm{pH}$ and suggests that the 


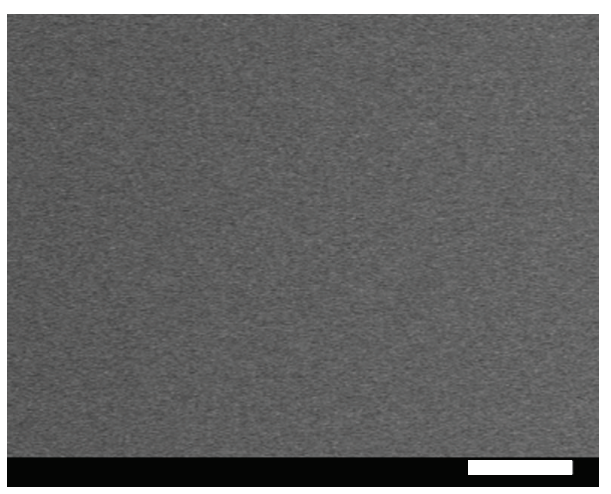

(a)

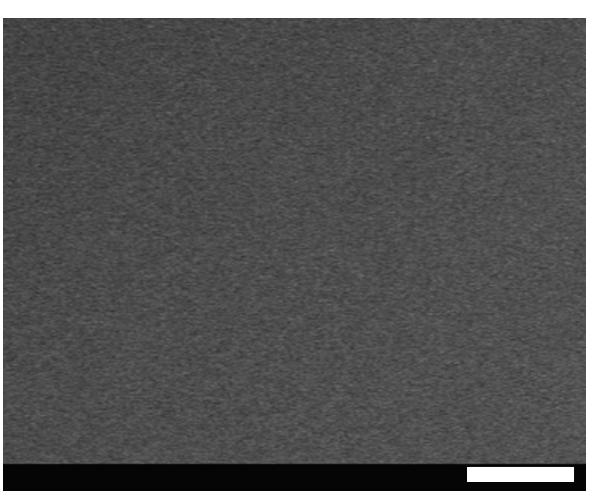

(b)

Figure 7: The surface images of the uncoated (a) and the coated PET bottles. The bar represents $1 \mu \mathrm{m}$.

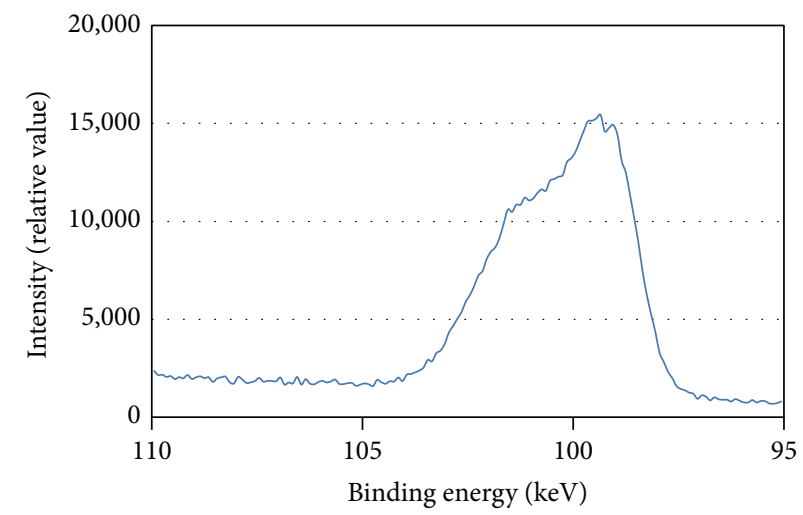

(a)

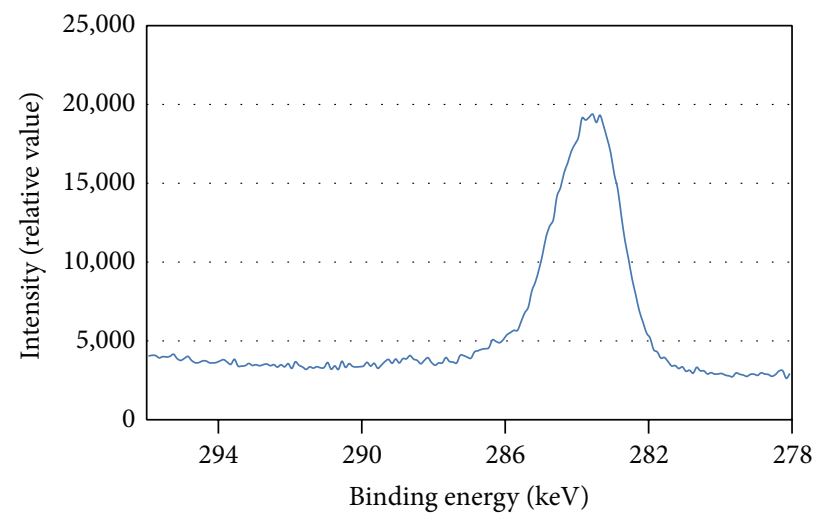

(c)

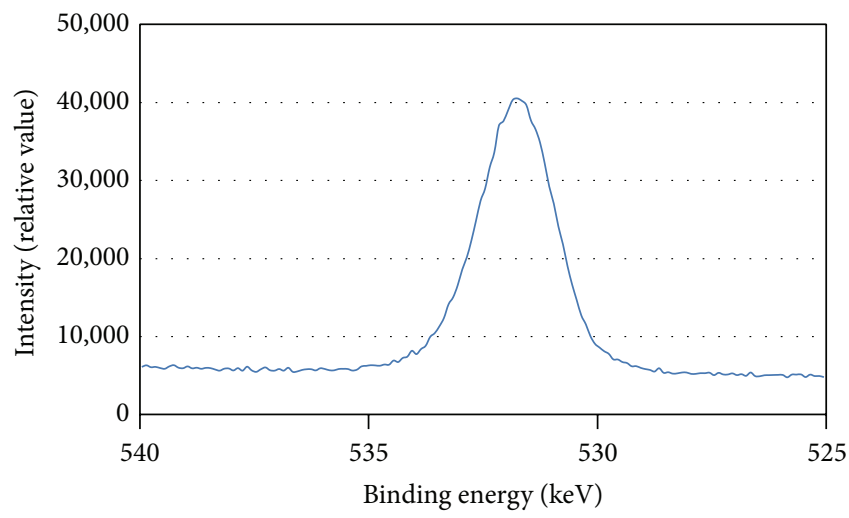

(b)

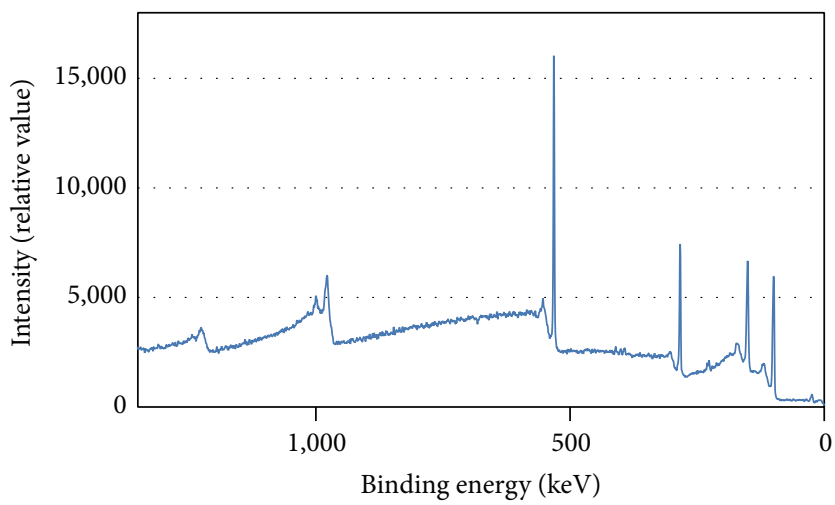

(d)

Figure 8: XPS spectra on (a) Si2p, (b) O1s, and (c) Cls and (d) the wide scan of the surface of thin film obtained.

storage period over 1 year indicates highly practical stability in contact with food and beverage applications.

\section{Discussion}

4.1. Basic Concepts of SiOC Coating Using Tantalum and Vinyl Silane. The approach described above was aimed at a breakthrough in coating technologies for the gas barrier enhancement of PET bottles and other plastic containers used for food and beverage products. In this field, conventional coatings are formed through plasma assisted CVD techniques and are limited in applications due to tint, gas barrier performance, or stability in contact with solutions close to neutral in terms of $\mathrm{pH}$.

For this aim, the authors made an attempt to form a gas barrier coating through a hot wire technique, where relatively simple formats of coating equipment are expected to improve economics for producing coated bottles. The key 


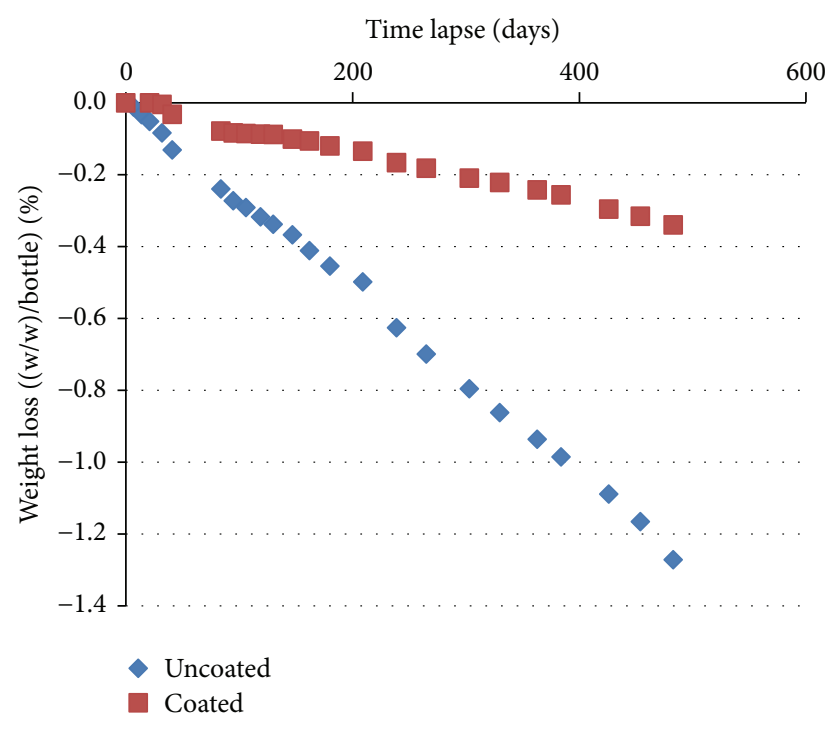

FIGURE 9: Water vapor loss from sealed PET bottles. $500 \mathrm{~g}$ of distilled water was filled with coated and uncoated PET bottles, and the decrease in the weight derived from water vapor permeation was measured regularly. The weight loss of $-1.0 \%$ refers to $5.0 \mathrm{~g}$ decrease from the initial weight.

issue for the economics and wide applicability of coating based on a hot wire technique lies in the combination of wire and material gas species [16]. Tantalum was mainly chosen due to heat resistance up to $2200^{\circ} \mathrm{C}$ and the general safe properties observed in medical applications [17]. Vinyl silane was mainly chosen due to its structure, economics, and expected safety in operations in food and beverage factories. The relatively small chemical structure of vinyl silane leads to its gaseous form under conditions around the atmospheric pressure and room temperature and facilitates simple coating equipment. Moreover, known typical material gas species for gas barrier hot wire coatings to polymer substrates such as hexamethyldisiloxane and hexamethyldisilazane seems to require high heat resistance to the substrate above the glass transition temperature of PET around $65^{\circ} \mathrm{C}$. Monosilane might be the most effective material gas for gas barrier coatings. The explosive nature of this chemical, however, seems difficult to use in the operations in food and beverage factories in terms of safety and related legal restrictions [18]. The presence of vinyl function in vinyl silane, to the contrary, prevents rapid reaction with oxygen in the atmospheric air and leads to the expectation in the safe operations. In brief, tantalum and vinyl silane potentially provide a novel and highly practical combination of wire and material gas species, respectively, for gas barrier hot wire coating of PET bottles for food and beverage applications.

The results of this study indicate that the SiOC thin film obtained is highly practical for those applications because a decreased restriction of applications can be expected. The BIF of the oxygen barrier of current coated PET bottles in this field is around 10 times [15]. Equivalent oxygen barrier performance was seen in the bottles coated with SiOC thin film obtained in this study, even with the coating time of
$2.0 \mathrm{sec}$. With this coating time, the appearance of the coated bottles was virtually colorless. It should be mentioned that when we remove the coating with caustic agents from the substrate as described in our previous study [15], we can confirm the slight tint is derived from the coating itself, not from any modifications in the matrix of the PET substrate. As a result, it is expected that these bottles do not have the restriction of applications seen in carbon coated bottles. This SiOC coating also showed unique properties in that the gas barrier performance was stable in contact with water. As a result, it is expected that these bottles do not have the restriction of applications seen in $\mathrm{SiOx}$ coated bottles, which tend to show decreased gas barrier properties in contact with neutral water solutions such as still water and tea products. In total, the SiOC coating in this study is likely to share the advantages of carbon (high gas barrier against oxygen, carbon dioxide, and water vapor even in contact with neutral water solutions) and $\mathrm{SiOx}$ (colorless) coatings.

4.2. Assumed Mechanism of SiOC Film Formation through the Hot Wire CVD Technique. XPS analysis conducted indicates silicate and carbon atoms contained in vinyl silane resulted in components of SiOC thin film formed in the above-mentioned experiment. It is considered that oxygen atoms contained in the SiOC thin film were derived from water vapor released from PET substrate rather than oxygen molecules which remained in the vacuum chamber through the vacuuming process, because the tint of the SiOC thin film was not affected when the pressure of the vacuum chamber before coating was decreased to $0.5 \mathrm{~Pa}$ (data not shown).

XPS analysis conducted also suggests hydrogen atoms associated with silicon atom in vinyl silane molecules were, partially or totally, disassociated in contact with hot tantalum wire and produced active fragments such as radicals, based on the presence of $\mathrm{Si}-\mathrm{Si}$ bonds in the SiOC thin film. This chemical reaction in coating seems to occur when the temperature of tantalum wire is above ca. $1600^{\circ} \mathrm{C}$. When the temperature was decreased from $2000^{\circ} \mathrm{C}$ to $1670^{\circ} \mathrm{C}$, deposition rate and the OTR of bottles coated with $30 \mathrm{~nm}$ thickness were gradually decreased from $4.6 \mathrm{~nm} / \mathrm{sec}$ to $2.2 \mathrm{~nm} / \mathrm{sec}$ and from $0.0016 \mathrm{cc}(\mathrm{STP}) / \mathrm{d} /$ bottle to $0.0040 \mathrm{cc}(\mathrm{STP}) / \mathrm{d} /$ bottle. However, when the temperature was further decreased to $1470^{\circ} \mathrm{C}$, deposition rate was remarkably decreased to $1.2 \mathrm{~nm} / \mathrm{sec}$, and the oxygen barrier of coated barrier was suddenly lost $(0.0331 \mathrm{cc}(\mathrm{STP}) / \mathrm{d} /$ bottle).

Whether or not this reaction between vinyl silane and hot tantalum is catalytic, as observed in catalytic chemical vapor deposition (Cat-CVD) techniques [19], remains to be answered but provides a remarkably interesting point of question. It seems that $\mathrm{Si}$-Si bonds are difficult to produce in typical plasma assisted CVD techniques, based on the result of XPS analysis conducted with a commercial plasma assisted CVD machine for PET bottle coating as disclosed in $[9,15]$ of this paper. In consideration of barrier enhancement effect of the result with the machine, it is obvious that a unique thin film deposition process occurs with the hot wire CVD process described in this paper, in comparison to typical plasma assisted CVD processes. It suggests that hot wire 
CVD processes can produce unique thin films which are difficult to form through plasma assisted CVD processes, and it can be expected that hot wire CVD processes provide novel benefits not only in terms of economics but also in terms of performance in plastic container applications. Further studies are required to clarify the advantages of the hot wire CVD described in this paper and other similar processes, compared to conventional processes.

\section{Conclusions}

A unique hot wire CVD technique using tantalum wire and vinyl silane gas was developed which is applicable to the surface coating of PET bottles.

Thin film coating using this technique functioned to enhance the gas barrier properties of PET bottles. The oxygen barrier improvement factor of coated bottles could be increased above 10 times, and their increased water vapor barrier property was stable in contact with water over 1 year. As a result, it was expected that this coating is highly practical in the applications of food and beverage plastic containers.

The coating formed was composed of silicon, carbon, and oxygen and characteristically contained $\mathrm{Si}-\mathrm{Si}$ bonds in its surface, possibly derived from a unique reaction between tantalum and vinyl silane.

\section{Competing Interests}

The authors declare that they have no competing interests.

\section{Acknowledgments}

The authors would like to express their gratitude to Professor Tetsuya Suzuki, Ph.D., Mr. Taku Aoki, and Tomoki Maeda, Ph.D., from Keio University for profound discussion. They are also thankful to all the staff related to this study in Keio University, Japan, Advanced Chemicals Co., Ltd., and Kirin Co., Ltd., Japan.

\section{References}

[1] A. Shirakura, M. Nakaya, Y. Koga, H. Kodama, T. Hasebe, and T. Suzuki, "Diamond-like carbon films for PET bottles and medical applications," Thin Solid Films, vol. 494, no. 1-2, pp. 8491, 2006.

[2] R. Downy, Evolving Global Demand and Opportunities for PET, Presentation at PETnology 2014, Nuernberg, Germany, 2014.

[3] A. Kazminova, A. Shelemin, M. Pert, O. Olylian, and H. Biederman, "Barrier Coatings on polymeric foils for food packaging," in Proceedings of the Contributed Papers, Part III (WDS '13), pp. 128-133, 2013.

[4] O. Brandan, "Hidden issues in barrier technology adaptations for converters and brandowners," in Proceedings of the Novapack, Orlando, Fla, USA, February 2010.

[5] H. Matsumura, "Formation of silicon-based thin films prepared by Catalytic Chemical Vapor Deposition (Cat-CVD) method," Japanese Journal of Applied Physics, Part 1, vol. 37, no. 6, pp. 31753187, 1998.
[6] A. Heya, T. Niki, Y. Yonezawa et al., "Highly moisture-resistive SiNx films prepared by catalytic chemical vapor deposition," Japanese Journal of Applied Physics, vol. 43, no. 10, pp. L1362L1364, 2004.

[7] K. Ohdaira and H. Matsumura, "Deposition of moisture barrier films by catalytic CVD using hexamethyldisilazane," Japanese Journal of Applied Physics, vol. 53, no. 5, Article ID 05FM03, 2014.

[8] Kyushu Institute of Technology, "Method for thin film formation," JP 4500961, 2004.

[9] K. B. Kabushiki Kaisha, "Apparatus for manufacturing dlc-filmcoated plastic container, method of manufacturing the same, and method for cleaning inner electrode," WO1996005112A1, 2002.

[10] Sidel, "Container with material coating having barrier effect and method and apparatus for making same," 1999, WO9949991A1.

[11] N. Boutroy, Y. Pernel, J. M. Rius et al., "Hydrogenated amorphous carbon film coating of PET bottles for gas diffusion barriers," Diamond and Related Materials, vol. 15, no. 4-8, pp. 921-927, 2006.

[12] KHS, "Multistation coating device and method for plasma coating," WO2003100121, 2003.

[13] A. G. Erlat, R. J. Spontak, R. P. Clarke et al., "SiOx gas barrier coatings on polymer substrates: morphology and gas transport considerations," Journal of Physical Chemistry B, vol. 103, no. 29, pp. 6047-6055, 1999.

[14] T. Kuroiwa, "Barrier technology-SiOx coating to the inside of the PET Bottle," JPI Journal, vol. 52, pp. 1006-1009, 2014.

[15] M. Nakaya, M. Shimizu, and A. Uedono, "Impact of the difference in power frequency on diamond-like carbon thin film coating over 3-dimensional objects," Thin Solid Films, vol. 564, pp. 45-50, 2014.

[16] R. Toukabri and Y. Shi, "Unraveling the complex chemistry using dimethylsilane as a precursor gas in hot wire chemical vapor deposition," Physical Chemistry Chemical Physics, vol. 16, no. 17, pp. 7896-7906, 2014.

[17] T. Hanawa, "Materials for metallic stents," Journal of Artificial Organs, vol. 12, no. 2, pp. 73-79, 2009.

[18] H.-Y. Tsai, S.-W. Wang, S.-Y. Wu, J.-R. Chen, E. Y. Ngai, and K. P. Huang, "Experimental studies on the ignition behavior of pure silane released into air," Journal of Loss Prevention in the Process Industries, vol. 23, no. 1, pp. 170-177, 2010.

[19] H. Matsumura, "Formation of silicon-based thin films prepared by catalytic chemical vapor deposition (Cat-CVD) method," Japanese Journal of Applied Physics, vol. 37, no. 6, pp. 3175-3187, 1998. 

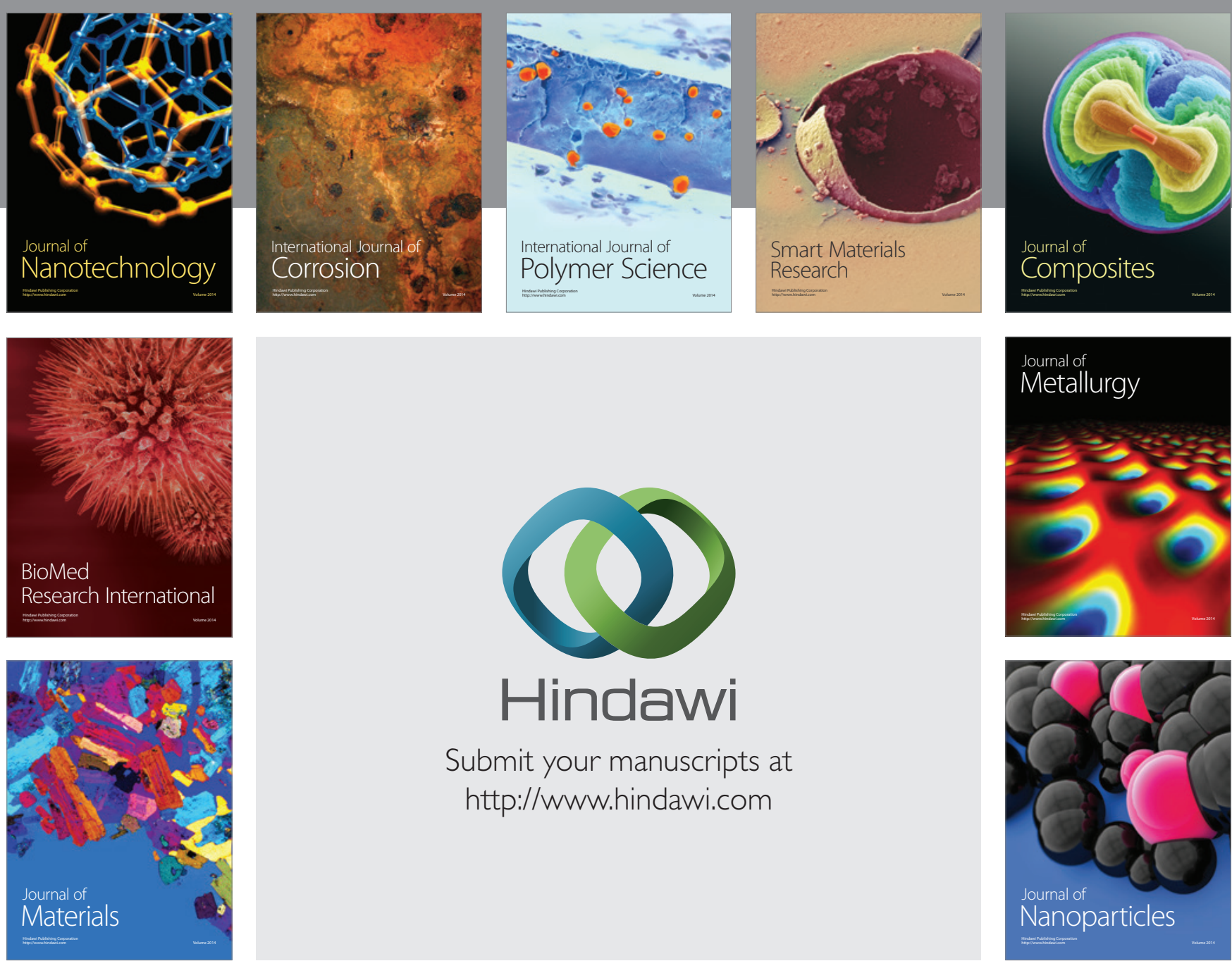

\section{Hindawi}

Submit your manuscripts at

http://www.hindawi.com

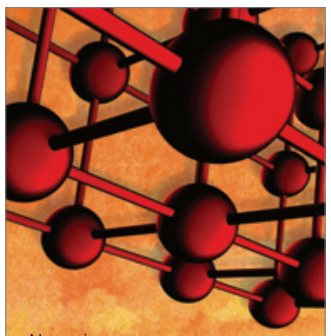

Materials Science and Engineering
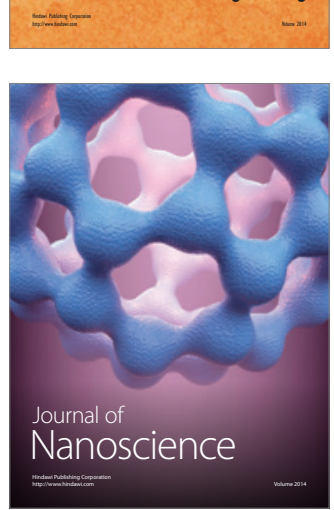
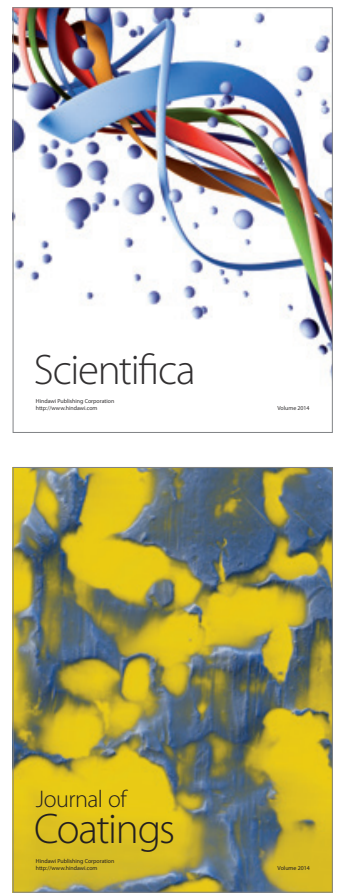
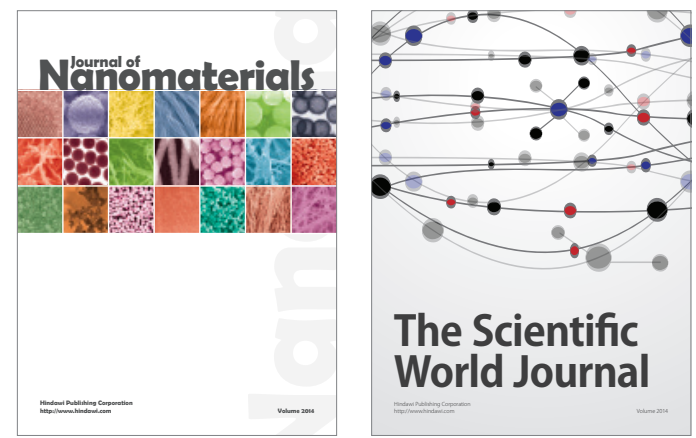

The Scientific World Journal
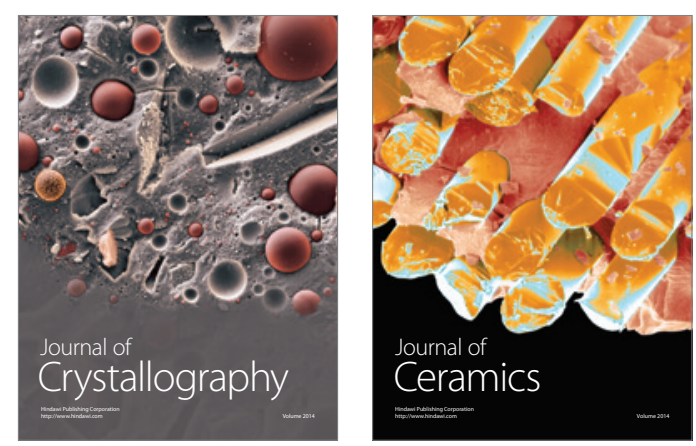
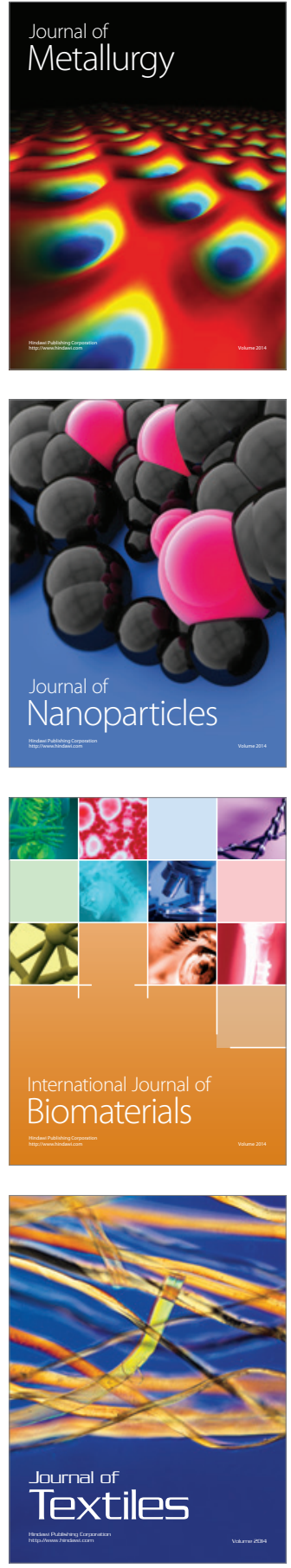